\title{
Long-Term Potentiation of Intrinsic Excitability at the Mossy Fiber- Granule Cell Synapse of Rat Cerebellum
}

\author{
S. Armano, ${ }^{1}$ P. Rossi, ${ }^{1}$ V. Taglietti, ${ }^{1}$ and E. D'Angelo ${ }^{1,2}$ \\ ${ }_{1}^{1}$ Department of Cellular/Molecular Physiology and Pharmacology, and INFM (Pavia Unit), I-27100 Pavia, Italy, and \\ 2Department of Functional and Evolutive Biology, Parco Area delle Scienze 11A, I-43100 Parma, Italy
}

Synaptic activity can induce persistent modifications in the way a neuron reacts to subsequent inputs by changing either synaptic efficacy or intrinsic excitability. After high-frequency synaptic stimulation, long-term potentiation (LTP) of synaptic efficacy is commonly observed at hippocampal synapses (Bliss and Collingridge, 1993), and potentiation of intrinsic excitability has recently been reported in cerebellar deep nuclear neurons (Aizenmann and Linden, 2000). However, the potential coexistence of these two aspects of plasticity remained unclear. In this paper we have investigated the effect of high-frequency stimulation on synaptic transmission and intrinsic excitability at the mossy fiber-granule cell relay of the cerebellum. High-frequency stimulation, in addition to increasing synaptic conductance (D'Angelo et al., 1999), increased granule cell input resistance and decreased spike threshold. These changes depended on postsynaptic depolarization and NMDA receptor activation and were prevented by inhibitory synaptic activity. Potentiation of intrinsic excitability was induced by relatively weaker inputs than potentiation of synaptic efficacy, whereas with stronger inputs the two aspect of potentiation combined to enhance EPSPs and spike generation. Potentiation of intrinsic excitability may extend the computational capability of the cerebellar mossy fiber-granule cell relay.

Key words: synaptic plasticity; LTP; NMDA receptors; cerebellum; granule cells; intrinsic excitability; E-S potentiation
In addition to causing transient modifications in neuronal potential, synaptic activity can induce changes in the way a neuron responds to subsequent inputs. This property, which is called synaptic plasticity, can entail persistent changes in both synaptic efficacy and intrinsic neuronal excitability. Although these two aspects of plasticity may concur to improve neuron and network computation (Fregnac, 1998), their potential coexistence remained unclear.

A well known model for synaptic plasticity is long-term potentiation (LTP), which is typically induced by high-frequency activation of NMDA receptors at glutamatergic synapses (Bliss and Collingridge, 1993; Bear and Malenka, 1994). Synaptic efficacy is enhanced during LTP. However, in hippocampal pyramidal cells the probability of action potential activation increases more than expected from potentiation of synaptic efficacy (E-S potentiation) (Bliss and Lömo, 1973; Andersen et al., 1980), suggesting that additional factors are involved. E-S potentiation was usually shown to depend on depression of synaptic inhibition (Abraham et al., 1987; Chavez-Noriega et al., 1990; Breakwell et al., 1996), although in some cases an intrinsic excitability change was suggested (Pugliese et al., 1994; Daoudal et al., 1999).

Activity-dependent changes in intrinsic excitability are common in the developing brain (Spitzer, 1991); their mechanisms have been investigated in cell culture (Turrigiano et al., 1994; Desai et al., 1999), and their computational implications have been predicted by using theoretical models (Stemmler and Koch, 1999). Recently, an NMDA receptor-dependent potentiation in intrinsic excitability has been observed in cerebellar deep nuclear neurons after high-frequency tetanic stimulation similar to that used to induce LTP, although in the absence of any synaptic efficacy changes (Aizenman and Linden, 2000).

We have investigated whether changes in intrinsic excitability could be induced by high-frequency stimulation of the mossy fiber-

\footnotetext{
Received Feb. 28, 2000; revised April 17, 2000; accepted April 25, 2000.

This work was supported by European Community Grants PL97 0182 and PL97 6060, and by INFM. We acknowledge Arianna Maffei and Elisabetta Sola for assistance with experiments.

Correspondence should be addressed to Dr. Egidio D'Angelo, Department of Cellular/Molecular Physiology and Pharmacology, Via Forlanini 6, I-27100 Pavia, Italy. E-mail: dangelo@unipv.it.

Copyright (C) 2000 Society for Neuroscience $0270-6474 / 00 / 205208-09 \$ 15.00 / 0$
}

granule cell synapse of the cerebellum, at which NMDA receptordependent LTP has recently been demonstrated (D'Angelo et al., 1999). After pharmacological blockage of inhibitory synapses, highfrequency stimulation induced an NMDA receptor-dependent potentiation of intrinsic excitability. This depended on a rise in input resistance and a decrease in spike threshold, which enhanced EPSPs and spike firing. Together with potentiation of synaptic conductance, potentiation of intrinsic excitability may play an important role in regulating granule cell synaptic excitation and cerebellar network computation.

\section{MATERIALS AND METHODS}

Acute $250-\mu \mathrm{m}$-thick cerebellar slices were obtained from 19- to-22-d-old Wistar rats as reported previously (D'Angelo et al., 1999). The rats were anesthetized with halothane (Aldrich, Milwaukee, WI) before being killed by decapitation. Slices were cut in the sagittal plane from the cerebellar vermis in cold Krebs' solution and maintained at room temperature before being transferred to a $1.5 \mathrm{ml}$ recording chamber mounted on the stage of an upright microscope (Zeiss Standard-16). The preparations were superfused with Krebs' solution and maintained at $30^{\circ} \mathrm{C}$ with a feedback Peltier device (HCC-100A; Dagan Corporation, Minneapolis MN).

The Krebs' solution contained (in $\mathrm{mm}$ ): $\mathrm{NaCl} 120, \mathrm{KCl} 2, \mathrm{MgSO}_{4} 1.2$, $\mathrm{NaHCO}_{3} 26, \mathrm{KH}_{2} \mathrm{PO}_{4} 1.2, \mathrm{CaCl}_{2} 2$, glucose 11 , and was equilibrated with $95 \% \mathrm{O}_{2}$ and $5 \% \mathrm{CO}_{2}, \mathrm{pH} 7.4$. The control and test solutions were applied locally through a multi-barrel pipette. Perfusion of the control solution was commenced before seal formation and was maintained until switching to the test solutions. Unless stated otherwise, the perfused solutions contained the GABA-A receptor blocker $10 \mu \mathrm{M}$ bicuculline. Nystatin and bicuculline were obtained from Sigma (St. Louis, MO), and the glutamate receptor antagonists D-2-amino-5-phosphonovaleric acid (APV), 7-chlorokinurenic acid (7-Cl-kyn), and 6-cyano-7-nitroquinoxaline-2,3dione (CNQX) were obtained from Tocris Cookson (Bristol, UK).

Whole-cell patch-clamp recordings were performed in granule cells using the perforated-patch technique, which prevents cytoplasmic washout (Horn and Marty, 1988; Edwards et al., 1989). The pipette solution contained (in mM): $\mathrm{K}_{2} \mathrm{SO}_{4} 80, \mathrm{NaCl} 10$, glucose 15 , HEPES 5 ( $\mathrm{pH}$ adjusted to 7.2 with $\mathrm{KOH}$ ), and nystatin $100 \mu \mathrm{g} / \mathrm{ml}$. Membrane potential was measured relative to an $\mathrm{Ag}-\mathrm{AgCl}$ reference electrode (Clark Instruments, Pangbourne, UK) and was not corrected for the Donnan potential developing across the patch $(-5 \mathrm{mV}$ inside the cell). Electrical activity was recorded with an Axopatch 200-B amplifier, sampled with a Digidata 1200B interface $(500 \mu \mathrm{sec} /$ point $)$, and analyzed off-line with P-Clamp software (Axon Instruments). The mossy fibers were stimulated with a bipolar tungsten electrode via a stimulus isolation unit.

In a typical experiment, mossy fibers were activated at a frequency of 0.1 $\mathrm{Hz}$, and step current pulses were applied every $5 \mathrm{~min}$ from the membrane potential of $-80 \mathrm{mV}$. High-frequency pulses were delivered $10 \mathrm{~min}$ after 


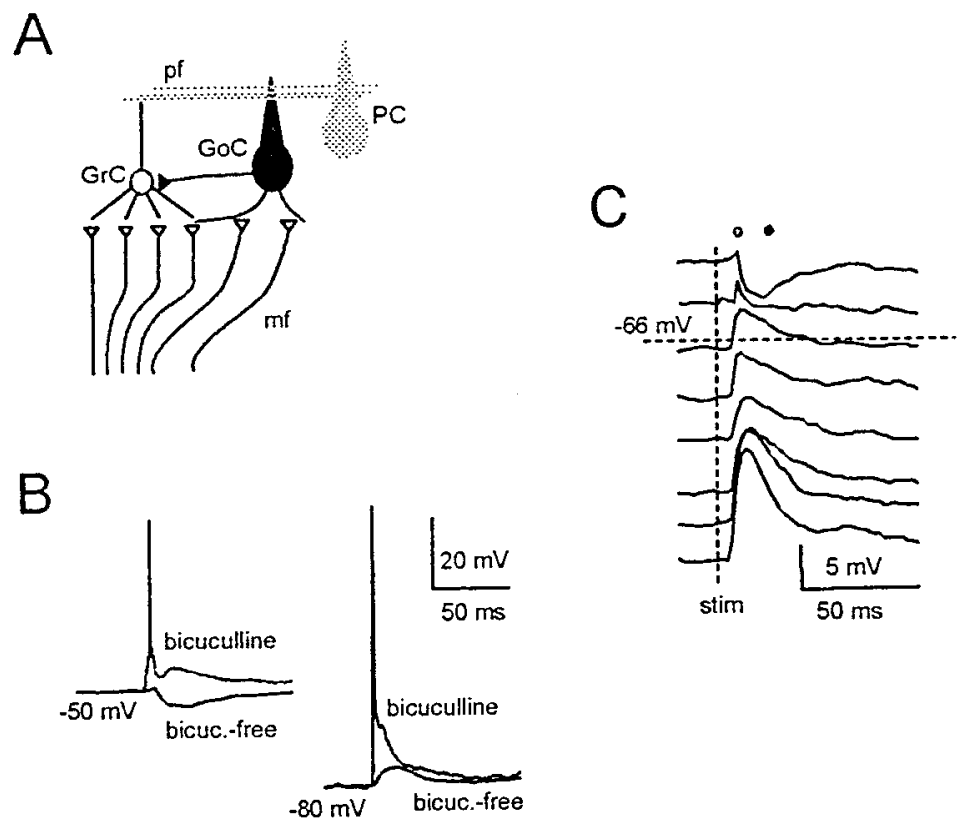

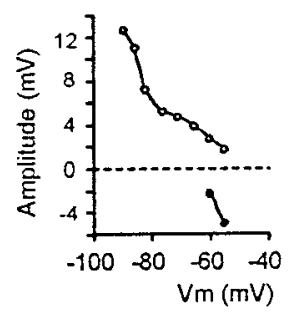

Figure 1. Synaptic excitation and inhibition of cerebellar granule cells. $A$, Schematic drawing of the cerebellar network. $G r C$, Granule cell; $G o C$, Golgi cell; $P C$, Purkinje cell; $m f$, mossy fiber; $p f$, parallel fiber. $B$, Granule cell synaptic responses elicited from two different membrane potentials before and after $10 \mu \mathrm{M}$ bicuculline application. Bicuculline enhanced EPSPs and spike generation. $C$, Granule cell synaptic responses elicited from different membrane potentials in bicuculline-free solution. The hyperpolarizing component of the response was present only above the $\mathrm{Cl}^{-}$equilibrium potential $(-66 \mathrm{mV})$. Amplitudes of the depolarizing (O) and hyperpolarizing $(-$ components of the response are plotted to the right (symbols over tracings indicate where measurements were taken). establishing the whole-cell recording configuration (time $=0$ ) either as a theta-burst stimulation (TBS; four $100 \mathrm{msec}, 100 \mathrm{~Hz}$ bursts of impulses repeated every $250 \mathrm{msec}$ ) or continuous stimulation (CS; one $1000 \mathrm{msec}$, $100 \mathrm{~Hz}$ burst of impulses) from potentials between -60 and $-90 \mathrm{mV}$

Membrane potential during step current injection was estimated as the average value between 500 and $800 \mathrm{msec}$. Membrane potential during TBS was estimated as the mean of average values measured in the central 70 msec of each burst (tracings were filtered at $100 \mathrm{~Hz}$ ). The action potentials consisted of two components, the prepotential and the upstroke (D'Angelo et al., 1998). The threshold of spike prepotential $\left(T h_{1}\right)$ was measured at the flexus in the interspike trajectory, whereas that of the upstroke $\left(T h_{2}\right)$ was measured at the sharp transition from prepotential to upstroke (see Fig. 5, inset). $T h_{1}$ coincided with the minimum depolarization necessary to activate an action potential, whereas $T h_{2}$ approached the depolarization reached by those prepotentials that did not initiate the ballistic phase of the action potential (examples are shown in Figs. $3 B, 4 A, B$, and $7 A$ ). In some cases, threshold identification was aided by taking the first time derivative of the signal (data not shown). Data are reported as mean $\pm \mathrm{SD}$, and statistical comparisons were performed using Student's $t$ test.

Just after obtaining the cell-attached configuration, electrode capacitance was carefully cancelled to allow for electronic compensation of pipette charging during subsequent current-clamp recordings (D'Angelo et al., 1995). The cerebellar granule cell is electrotonically compact and can be treated as a simple RC system, in which relevant parameters can be extracted by analyzing passive current relaxation induced by step voltage changes (D'Angelo et al., 1995, 1999; Silver et al., 1996). Monoexponential fitting to current transients elicited by $10 \mathrm{mV}$ hyperpolarizing voltage steps from the holding potential of $-80 \mathrm{mV}$ yielded the voltage-clamp time constant, $\tau_{\mathrm{VC}}$. The input capacitance $\left(C_{\mathrm{in}}\right)$ was measured from the capacitive charge (the area underlying current transients), and series resistance $\left(R_{\mathrm{s}}\right)$ was calculated as $R_{\mathrm{s}}=\tau_{\mathrm{VC}} / C_{\mathrm{in}}$. Input resistance $R_{\mathrm{in}}$ was computed from the steady current flowing after termination of the transient. When the patch perforation had stabilized, typical granule cell values were obtained $\left[C_{\text {in }}=3.1 \pm 0.7 \mathrm{pF}, R_{\mathrm{in}}=2.3 \pm 0.5 \mathrm{G} \Omega\right.$, and $R_{\mathrm{s}}=34.3 \pm 17.2$ $\mathrm{M} \Omega(n=18$ for all measurements)].

Current-clamp recordings were performed in the "fast" operating mode to optimize the reaction rate of the amplifier (D'Angelo et al., 1998; Magistretti et al., 1998). The effect of $R_{\mathrm{s}}$ in current-clamp recordings is inversely proportional to $R_{\text {in }}$. Because $R_{\mathrm{s}}$ was approximately two orders of magnitude smaller than $R_{\mathrm{in}}$, the effect of $R_{\mathrm{s}}$ on voltage recordings was negligible $(\sim 1 \%)$. For this reason, (1) perforated-patch recordings were at no disadvantage to ruptured-patch recordings despite $R$ being nearly $50 \%$ higher; (2) bridge balancing was unnecessary, and (3) recording stability was ensured despite changes in $R_{\mathrm{s}}$ that might occur during prolonged recordings. Recording stability was attested by $R_{\text {in }}$ measurements, as shown in Figure 4.

Although perforated-patch recordings prevent cytoplasmic constituents from being washed out, EPSP size and spike threshold showed a slow time-dependent decrease (see Figs. $2 C, 3 C, 4 C$ ). This may reflect long-term modifications induced by spike discharge (Pockett et al., 1990; Christofi et al., 1993; Aizenmann and Linden, 2000) generated by step current pulses used to monitor granule cell intrinsic excitability.

\section{RESULTS}

The effect of high-frequency mossy fiber stimulation on synaptic efficacy and intrinsic granule cell excitability was investigated in rat cerebellar slices at P19-P22, when granule cells show mature synaptic and excitable properties (D’Angelo et al., 1998), using whole-cell perforated-patch recordings (Horn and Marty, 1988).

\section{Preliminary observations}

Granule cells are excited by glutamatergic mossy fiber synapses and inhibited by GABAergic Golgi cell synapses (Fig. 1A). EPSPs recorded with $10 \mu \mathrm{M}$ bicuculline in the bath to block GABA-A receptors (Fig. $1 B$ ) measured between 8 and $22 \mathrm{mV}$ in different experiments (compare Fig. 2). Considering that cerebellar granule cells receive four mossy fiber inputs on average (Eccles et al., 1967), each causing an 8-12 mV depolarization (D'Angelo et al., 1995; Silver et al., 1996), one to three mossy fiber synapses should have been activated. Golgi cells can be activated directly by mossy fibers in the glomeruli, as well as by granule cell axons, the parallel fibers (Eccles et al., 1967). Mossy fiber stimulation in bicuculline-free solution (i.e., with unblocked GABA-A receptors) caused strong granule cell inhibition, curtailing EPSPs and preventing spike generation (cf. tracings obtained before and after bicuculline application in Fig. $1 B$ ). Because parallel fibers are severed in sagittal slices, Golgi cells should be preferentially activated through their mossy fiber input rather than through the granule cell-parallel fiber recurrent loop. Consistently, inhibition arose quickly (3-5 msec), whereas longer delays would be expected for feedback inhibition (Vos et al., 1999). IPSPs were evident at potentials positive to $-64.2 \pm 3.3 \mathrm{mV}(n=5)$ (Fig. $1 C)$, above the chloride equilibrium potential $(-66 \mathrm{mV})$ (see Materials and Methods) and the granule cell resting potential $(-63.6 \pm 8.9 \mathrm{mV} ; n=10)$. Because GABAergic responses have a depolarizing action below the chloride equilibrium potential, the marked EPSP reduction observed in this membrane potential range indicates that GABA receptors act through a shunting mechanism to decrease granule cell input resistance. GABA-A receptors may also operate through a tonic inhibition mechanism (Brickley et al., 1996), because granule cell input resistance was $28 \%$ lower before bicuculline perfusion than after it $(1.8 \pm 0.7 \mathrm{G} \Omega$ vs $2.5 \pm 1.7 \mathrm{G} \Omega ; n=7)$.

Mossy fibers convey complex patterns of high-frequency spike bursts during movement (Kase et al., 1980) and can entrain the granular layer to discharge at theta frequency (Pellerin and Lamarre, 1997; Hartmann and Bower, 1998). In preliminary experiments we observed that LTP was similar when it was induced by high-frequency stimulation organized either in repeated bursts (TBS) or in a single continuous burst (CS) (Table 1). TBS was thus preferred because it allowed a closer comparison with previous voltage-clamp experiments (D’Angelo et al., 1999). 
$\mathrm{A}_{1}$

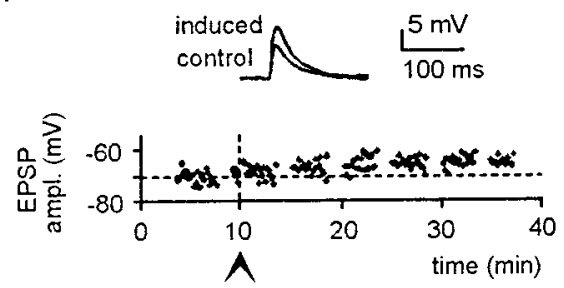

$\mathrm{A}_{2}$

Figure 2. LTP of excitatory transmission. $A_{1}, A_{2}$, Effect of TBS delivered from $-70 \mathrm{mV}$ in a solution containing $10 \mu \mathrm{M}$ bicuculline. Control EPSPs activated from $-80 \mathrm{mV}$ measured $9.1 \pm 3.2 \mathrm{mV}$ in $A_{1}$ and $21.2 \pm 4.3 \mathrm{mV}$ in $A_{2}$. LTP was manifest as an EPSP increase, which was larger in $A_{2}$ than $A_{1}$. In $A_{2}$, EPSP growth led to spike generation 7 min after TBS. $B_{1}$ and $B_{2}$, Membrane depolarization during TBS corresponding to recordings in $A_{1}, A_{2}$. Note stronger depolarization and spike generation in $B_{2}$ than $B_{1}$. $C$, Average EPSP potentiation in five cells as in $A_{1}(\bullet)$ and in five cells as in $A_{2}(\bigcirc$; the point series is interrupted because of spike generation). Results are compared with control EPSP recordings in which no TBS was applied $(\Delta ; n=5) . D$, Potentiation of the probability of firing during LTP in cells showing spikes during the control period $(n=8)$. In this and the following figures, an arrowhead $(>)$ and a vertical dotted line indicate TBS. Data points are reported as mean $\pm \mathrm{SD}$, and time is relative to beginning of recordings.

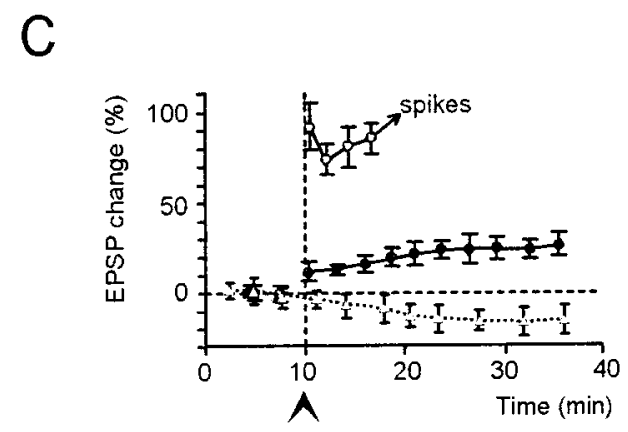

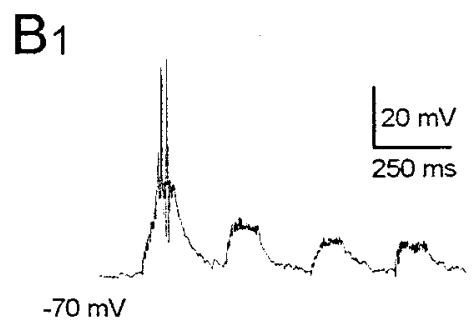

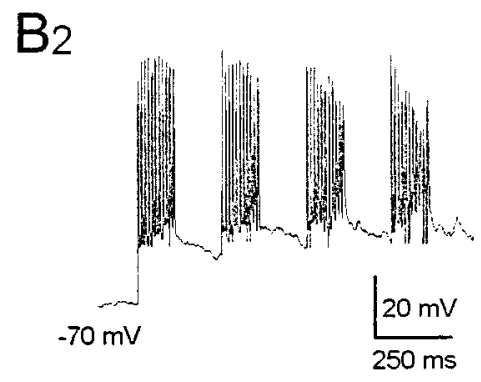

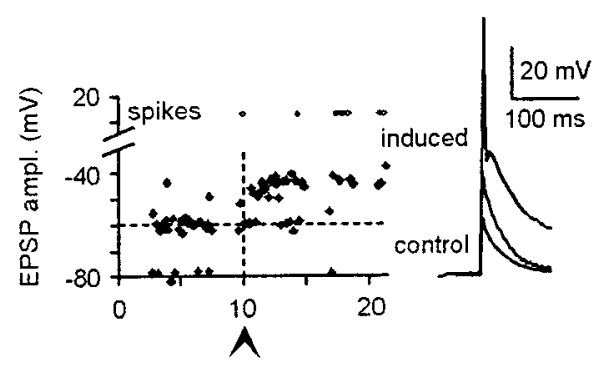

$\mathrm{D}$

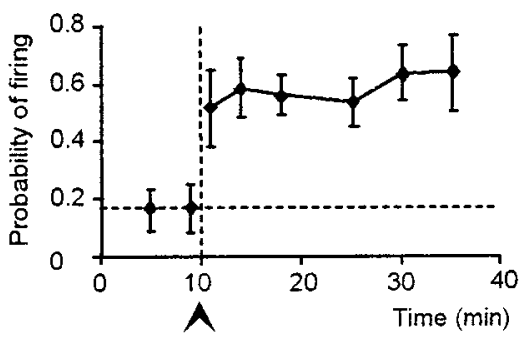

Table 1. Effect of TBS and CS on synaptic efficacy and intrinsic excitability

\begin{tabular}{|c|c|c|c|c|c|}
\hline & & \multicolumn{2}{|c|}{ Bicuculline $10 \mu \mathrm{M}$} & \multicolumn{2}{|l|}{ Bicuculline free } \\
\hline & & TBS & $\mathrm{CS}$ & TBS & $\mathrm{CS}$ \\
\hline EPSC amplitude & (\% change) & $32 \pm 13(10)^{a}$ & $25 \pm 15(5)^{b}$ & & \\
\hline EPSP amplitude & (\% change) & $84 \pm 16(5)$ & $75 \pm 19(4)$ & $-2.3 \pm 4.5(6)$ & $-7.2 \pm 9.6(5)$ \\
\hline$R_{\text {in }}$ & (\% change) & $37 \pm 33(10)$ & $41 \pm 23(5)$ & $-0.06 \pm 0.5(6)$ & $-10 \pm 14.3(5)$ \\
\hline$T h_{1}$ & $(\mathrm{mV})$ & $-7.9 \pm 3.5(10)$ & $-9.1 \pm 3.8(5)$ & $1.8 \pm 1.9(6)$ & $1.6 \pm 2.4(5)$ \\
\hline
\end{tabular}

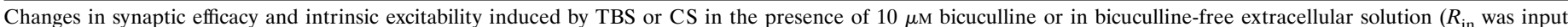

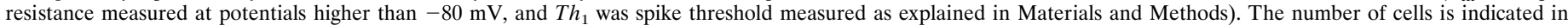

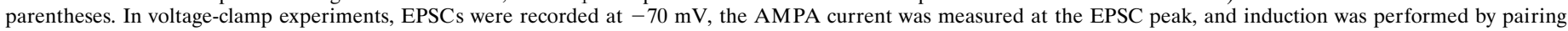

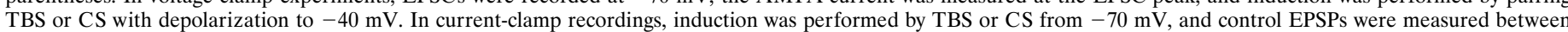

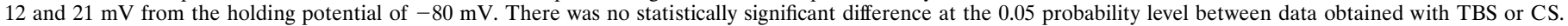

${ }^{a}$ From D'Angelo et al. (1999).

${ }^{b}$ Obtained as in D'Angelo et al. (1999), except that CS was paired with $1 \mathrm{sec}$ depolarization at $-40 \mathrm{mV}$.

\section{EPSP potentiation}

In an initial set of experiments, LTP was investigated during GABA-A receptor blockage by $10 \mu \mathrm{M}$ bicuculline. LTP recordings were grouped depending on membrane depolarization efficiency during TBS, which in turn depended on the initial EPSP size (Fig. 2, Table 2).

In the first group, TBS had a weak depolarizing action $(n=5)$ (Fig. $2 A_{1}, B_{1}$ ). A few spikes could be elicited in the first TBS burst in three of five cells, and depolarization tended to decrease in subsequent bursts (Fig. 2). After TBS, EPSP amplitude increased over control values by $23 \pm 14 \%(n=5 ; p<0.01)$ in $15 \mathrm{~min}$ (Fig. $\left.2 A_{1}, C\right)$.

In a second group, TBS caused a strong granule cell excitation $(n=5)$ (Fig. $\left.2 A_{2}, B_{2}\right)$. Robust action potential discharge was generated in all TBS bursts (Fig. 2). After TBS, EPSPs increased by $84 \pm 16 \%(p<0.01 ; n=5)$ over control values in $\sim 7 \mathrm{~min}$, and most of them then elicited action potentials (Fig. $2 A_{2}, C$ ). In a different set of cells showing strong TBS $(n=8)$, action potentials were occasionally generated by control EPSPs $(19.7 \%)$ and became more frequent after LTP, precluding EPSP changes from being measured. In these recordings, after TBS, the probability of action potential generation increased by $120 \pm 85 \%$ over control values in 15 min $(p<0.01 ; n=8)$ (Fig. $2 D)$, and in many cases spikes occurred in doublets or triplets (data not shown).

Thus, although EPSP potentiation was observed in all cases, it was of different magnitude depending on the initial EPSP size and 
Table 2. Effect of TBS strength on EPSP potentiation

\begin{tabular}{lcclll} 
& \multicolumn{3}{l}{ TBS } & \\
\cline { 4 - 5 } & $n$ & $\begin{array}{l}\text { EPSP } \\
(\mathrm{mV})\end{array}$ & $\begin{array}{l}\text { m.b.d. } \\
(\mathrm{mV})\end{array}$ & s.f. $(\mathrm{Hz})$ & $\begin{array}{l}\text { LTP }(\% \\
\text { EPSP change })\end{array}$ \\
\hline Weak TBS & 5 & $9.2 \pm 1$ & $-56 \pm 6.5$ & $13 \pm 15$ & $23 \pm 14$ \\
Strong TBS & 5 & $14.6 \pm 4.8$ & $-38 \pm 4.9$ & $71 \pm 14$ & $84 \pm 16$
\end{tabular}

Recordings were parsed according to the efficiency of granule cell synaptic excitation during TBS, which was expressed as mean burst depolarization (m.b.d.) and spike frequency (s.f.). "Weak TBS" corresponds to data in Figure 2, $A_{1}$ and $B_{1}$, "strong TBS" corresponds to data in Figure 2, $A_{2}$ and $B_{2}$, and average LTP time courses are summarized in Fig. $2 C$. EPSP potentiation was higher after strong than weak TBS. It should be noted that the initial EPSP size was comparatively smaller when weak rather than strong TBS was observed. Data in the two groups were significantly different $(p<$ $0.01)$.

A

control

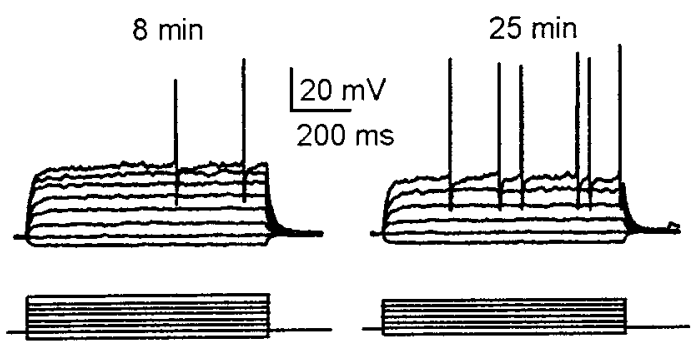

B

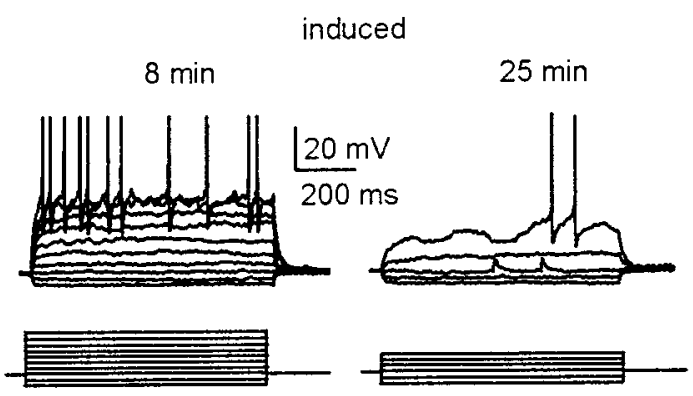

C

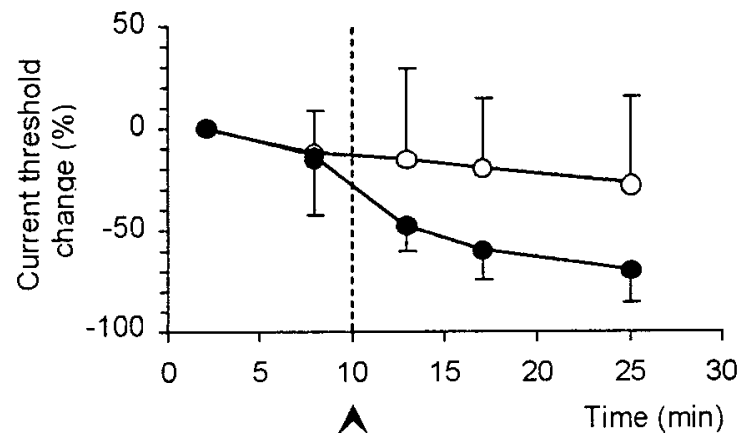

Figure 3. Enhanced action potential generation during LTP. Granule cell responses to current injection (bottom tracings, $2 \mathrm{pA} / \mathrm{step}$ ) from $-80 \mathrm{mV}$ are compared in $(A)$ control recordings and in $(B)$ recordings in which LTP was induced (this cell was one of those included in Fig. $2 A_{1}$ ). Tracings were taken 8 and $25 \mathrm{~min}$ after the beginning of recordings. $C$, Time course of the current needed to fire action potentials (current threshold) in control recordings $(\bigcirc ; n=5)$ and in recordings in which LTP was induced $(\mathbf{O} ; n=$ 10). Note the marked decrease in current threshold during LTP.
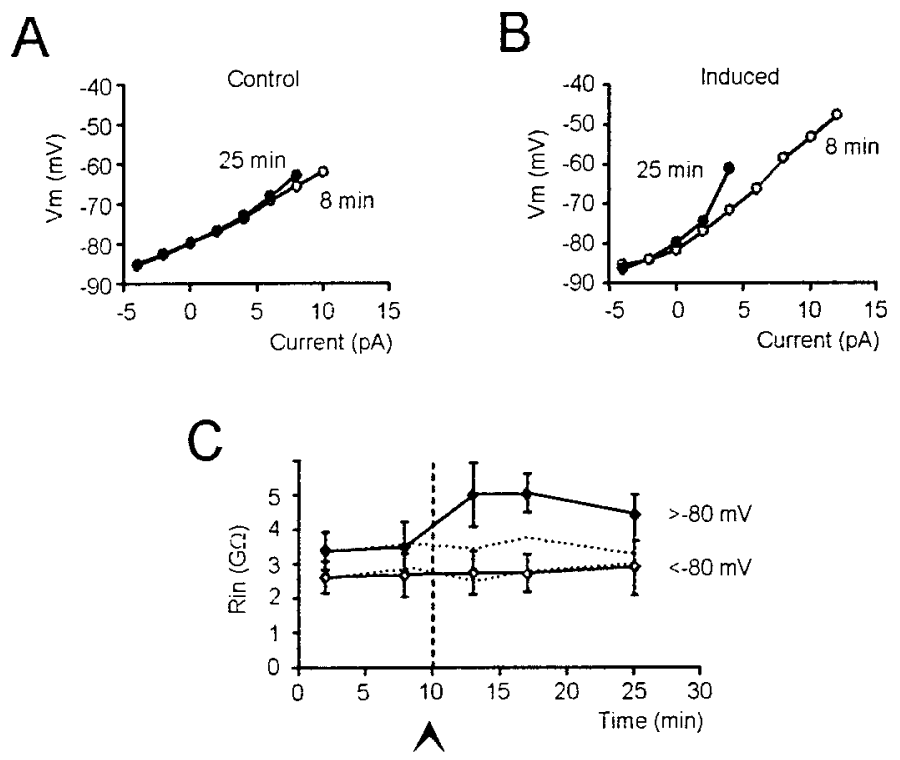

Figure 4. Increased input resistance during LTP. $A, B$, Voltage-current plots have been constructed by measuring steady-state depolarization in the tracings of Figure $3, A$ and $B$, respectively $(O 8 \mathrm{~min}$ and $25 \mathrm{~min}$ after beginning of recordings). $C$, Time course of $R_{\text {in }}$ in control recordings (dotted line $n=5$; SD was between 0.5 and $0.7 \mathrm{G} \Omega$ ) and in recordings in which LTP was induced (solid line; $n=7$ ). Note that after LTP induction, $R_{\text {in }}$ increased at potentials higher (54) but not lower (55) than $-80 \mathrm{mV}$. In control recordings $R_{\text {in }}$ remained stable in both potential ranges.

the excitatory action of TBS (see also below). It should be noted that control EPSPs tended to decrease slightly with time $(-17.2 \pm$ $11.4 \%$ after 20 min recordings; $n=5$ ) (Fig. 2C), probably reflecting simultaneous synaptic depression (Pockett et al., 1990; Christofi et al., 1993).

\section{Potentiation of intrinsic membrane excitability}

Cerebellar granule cells injected with step depolarizing currents showed inward rectification in the subthreshold membrane potential region and, once the threshold was reached, generated a repetitive spike discharge (D'Angelo et al., 1995, 1998) (Fig. 3A). After TBS, action potential generation was enhanced, and enhanced depolarization associated with membrane potential oscillations could often be observed in the threshold region (Figs. $3 B, 5 B, 7 A$ ). The current needed to generate spikes (current threshold) decreased (Fig. $3 A, B$ ), becoming significantly smaller than in control recordings $(-70 \pm 16 \% 15 \mathrm{~min}$ after TBS; $n=10 ; p<0.03)$ (Fig. $3 C$ ). Because GABA-A receptors were blocked, the reduction in current threshold reflected a potentiation of intrinsic granule cell excitability. The mechanism of excitability potentiation was further investigated by measuring changes of apparent granule cell input resistance $\left(R_{\mathrm{in}}\right)$ and of action potential threshold in the experiments of Figure $2 C$ (those in Fig. $2 D$ had a similar behavior; data not shown).

$R_{\text {in }}$ was measured from membrane potential changes caused by current steps in the $10 \mathrm{mV}$ potential range either below or above $-80 \mathrm{mV}$ (Fig. $4 A, B$ ). After TBS, $R_{\text {in }}$ rapidly increased above -80 $\mathrm{mV}$, whereas $R_{\text {in }}$ remained unchanged below $-80 \mathrm{mV}$ (Fig. $4 C$ ). The $R_{\text {in }}$ increase reached $37 \pm 33 \% 15$ min after TBS $(n=10 ; p<$ $0.03)$.

Action potential threshold was measured both at the beginning of spike prepotential $\left(T h_{1}\right)$ and at the beginning of upstroke $\left(T h_{2}\right)$ (Fig. 5, inset) (D'Angelo et al., 1998). After TBS, both thresholds decreased, becoming significantly lower than in control recordings $(n=10 ; p<0.05)$ (Fig. $5 A-C)$. Because $T h_{1}$ decreased more than $T h_{2}$ (Fig. $\left.5 C\right)$, the spike prepotential was enhanced $(4.1 \pm 3.2 \mathrm{mV}$ 15 min after TBS; $n=10 ; p<0.03$ ) (Fig. 5D).

These results indicated that an increase in $R_{\mathrm{in}}$ and a decrease in spike threshold combined to reduce the current needed to fire 


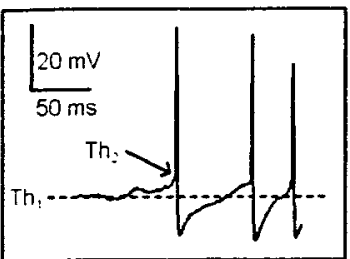

A

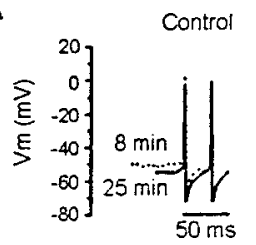

B

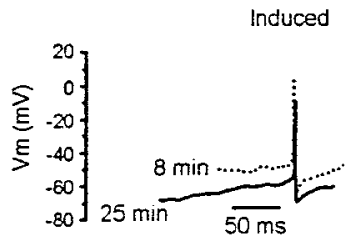

Figure 5. Decreased spike threshold during LTP. The inset shows where the thresholds of spike prepotential $\left(T h_{1}\right)$ and spike upstroke $\left(T h_{2}\right)$ were measured. $A, B$, Spikes in control recordings $(A)$ and in recordings in which LTP was induced $(B)$. Tracings were taken 8 and 25 min after beginning recordings from the same cells shown in Figure 3. $C$, Time course of threshold changes in control recordings $(n=5$; dotted line; the SD was between 4 and $6 \mathrm{mV}$ ) and in recordings in which LTP was induced $(n=$ 10). $D$, Greater decrease in $T h_{1}$ than $T h_{2}$ caused an enlargement of spike prepotential during LTP $(\mathbf{\bullet} ; n=10$; control recordings $35 ; n=5)$.
C

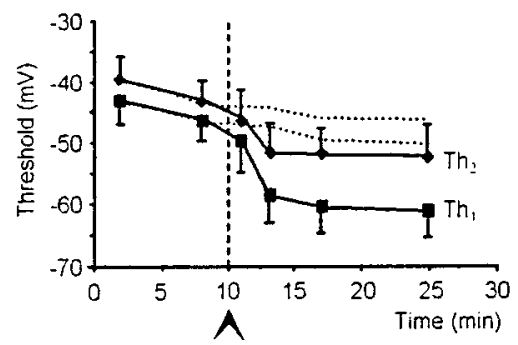

D

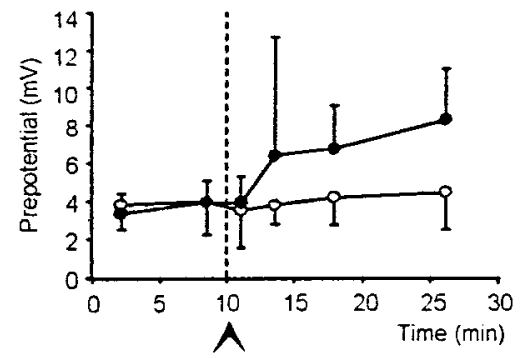

A

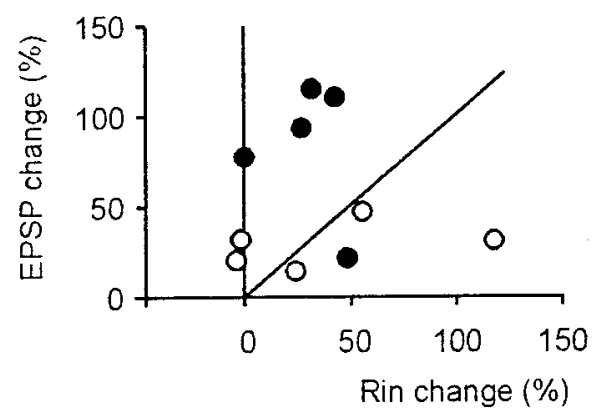

$\mathrm{B}$

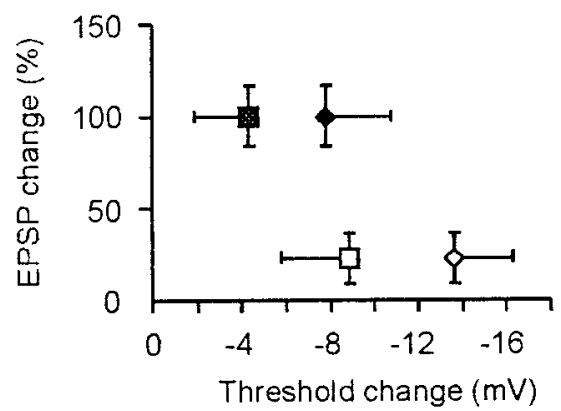

Figure 6. Relationship between EPSP and intrinsic excitability potentiation. $A$, Plot of EPSP versus $R_{\text {in }}$ changes at potentials higher than $-80 \mathrm{mV}$. The diagonal is the place where EPSP equals $R_{\text {in }}$ changes, $\bigcirc$ corresponds to weak TBS (same experiments as in Fig. $2 A_{1}, B_{1}$ ), and corresponds to strong TBS (same experiments as in Fig. $2 A_{2}, B_{2}$ ). $B$, Plot of EPSP versus $T h_{1}$ (圈, strong TBS, $n=5$; $\square$, weak TBS, $n=5$ ) and $T h_{2}(\diamond$, strong TBS $n=5$; $\diamond$, weak TBS, $n=5$ ) changes. $T h_{1}$ and $T h_{2}$, which were measured in the same cells included in Figure $2 C$ and Table 2, were corrected for time-dependent changes in control recordings. Note that changes in $R_{\mathrm{in}}$, $T h_{1}$, and $T h_{2}$ were already appreciable, with relatively small EPSP changes. All data in this figure were recorded 15 min after TBS. action potentials during LTP (similar results could be obtained using CS rather than TBS) (Table 1).

\section{Relationship between potentiation of EPSPs and intrinsic excitability}

The relationship between $R_{\text {in }}$ and EPSP potentiation is shown in the plot in Figure $6 A$, in which the diagonal represents an equal increase in EPSP and $R_{\text {in }}$. The presence of points either above or below the diagonal indicated that the $R_{\text {in }}$ increase could be associated with an increase or decrease in synaptic conductance, respectively. Moreover, points falling on the $y$-axis reflected a pure synaptic conductance increase. It should be noted that points falling above the diagonal were more frequently observed after strong (Fig. 6 $A, 0$ ) rather than weak (Fig. 6 $A, \bigcirc$ ) TBS bursts. Strong TBS should therefore be needed to obtain a reliable synaptic conductance potentiation (also see Fig. 9).

The relationship between the spike threshold and EPSP potentiation (Fig. $6 B$ ) showed that the spike threshold was significantly reduced after either weak or strong TBS (Fig. $6 B$ ). Thus, as with the $R_{\text {in }}$ increase, the decrease in spike threshold occurred at a lower threshold than potentiation of synaptic transmission.

\section{Effect of synaptic inhibition on LTP}

An important role in LTP regulation is played by inhibitory synapses. In the hippocampus, synaptic inhibition has the dual role of preventing LTP induction (Davies et al., 1991) and enhancing postsynaptic responsiveness through its own depression during LTP (Abraham et al., 1987; Chavez-Noriega et al., 1990; Breakwell et al., 1995). In the cerebellum, LTP properties may be regulated by inhibitory Golgi synapses (compare Fig. 1).

Figure $7 A$ shows recordings from a granule cell in which TBS was delivered in bicuculline-free solution to allow synaptic inhibition of the granule cell. In this condition, TBS caused very weak depolarization, and no LTP was induced. After $10 \mu \mathrm{M}$ bicuculline perfusion, TBS caused robust action potential discharge, inducing normal LTP. Average results obtained in five recordings in bicucullinefree solution are shown in Figure $7 B, C$. Burst membrane potential during TBS settled at $-2.1 \pm 9.2 \mathrm{mV}(n=5)$, close to the $\mathrm{Cl}^{-}$ reversal potential. EPSP, $R_{\text {in }}$, and spike threshold showed no significant potentiation. GABA-A receptor-mediated synaptic inhibition therefore exerted strong preventative action on mossy fibergranule cell LTP (similar results were obtained using CS rather than TBS) (Table 1).

\section{The role of membrane depolarization}

Membrane depolarization is a fundamental factor in the induction of synaptic plasticity (Kelso et al., 1986). Indeed, the results re- 
A
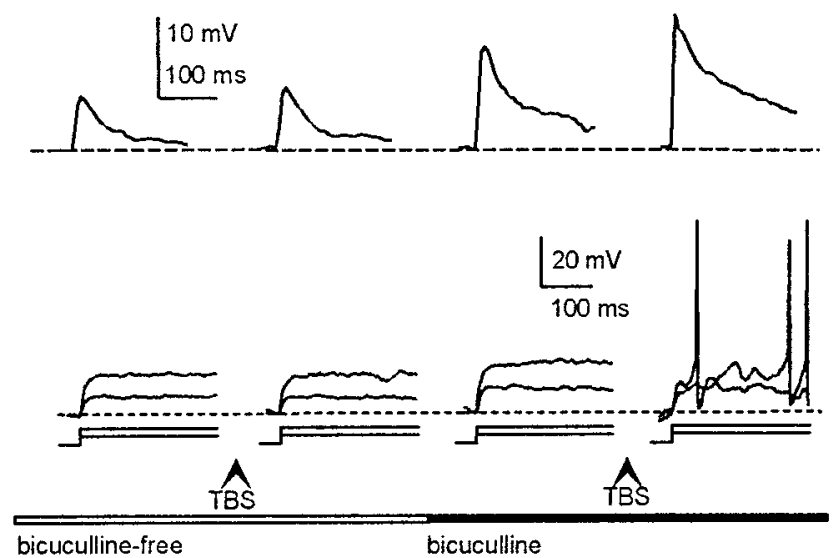

bicuculline-free

bicuculline

C

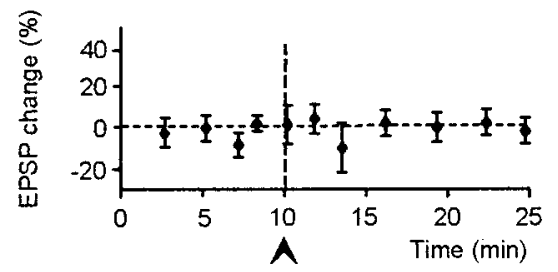

A

C
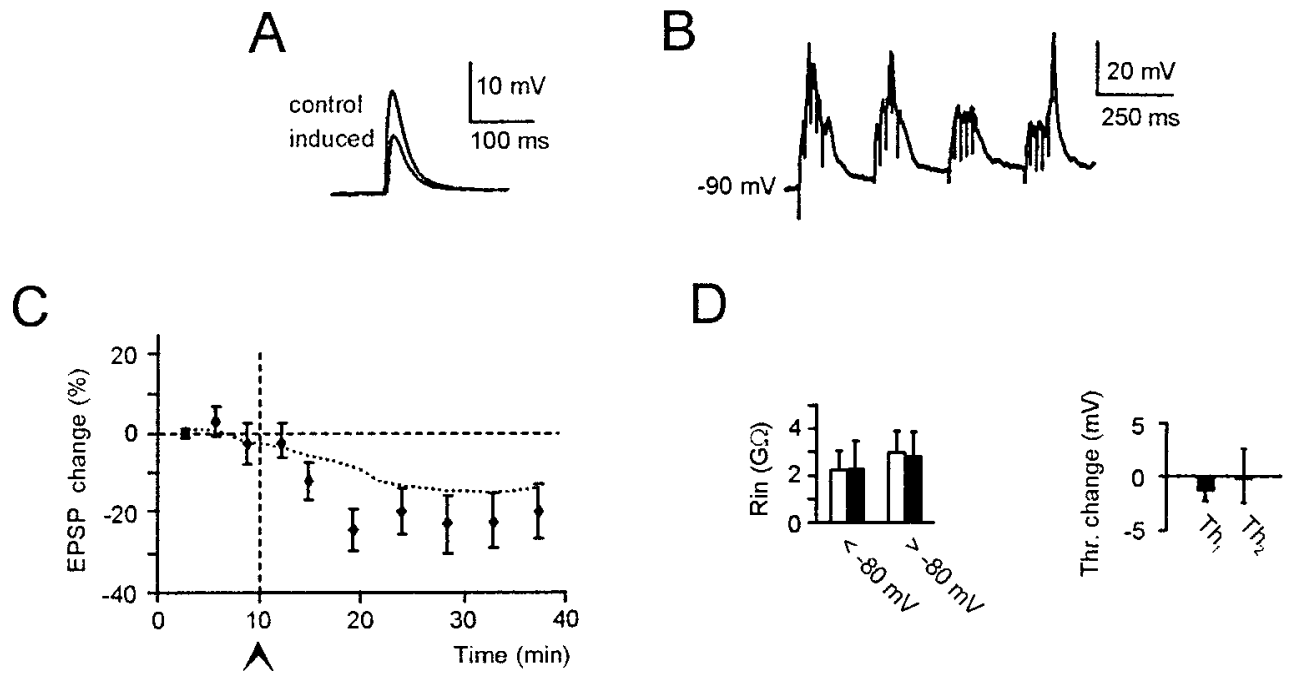

B
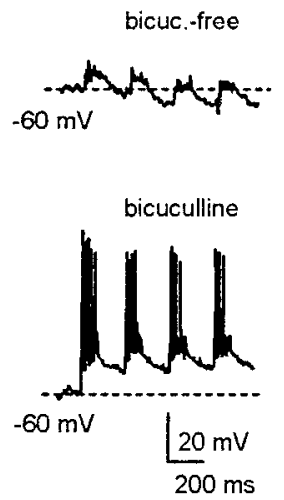

Figure 7. Synaptic inhibition prevents LTP. Effect of TBS during perf usion of a bicuculline-free solution. $A, B$, Tracings in $A$ [EPSPs (top row) and responses to 4 and $8 \mathrm{pA}$ current steps (bottom row); indicates application of TBS] and $B$ (membrane depolarization during TBS) illustrate one of two experiments in which recordings lasted long enough to allow a second TBS to be applied during subsequent $10 \mu \mathrm{M}$ bicuculline perfusion. LTP, comprising EPSP and intrinsic excitability potentiation, could be elicited in the presence but not in the absence of bicuculline. $C$, Average EPSP changes in six cells after TBS in bicuculline-free solution. $D, R_{\text {in }}$ changes (both above and below $-80 \mathrm{mV}$ ) and changes in $T h_{1}$ and $T h_{2}$ corrected for time-dependent changes in control recordings. All data were recorded $15 \mathrm{~min}$ after TBS (same cells as in $C$ ).

Figure 8. Membrane hyperpolarization prevents LTP. Effect of TBS delivered from $-90 \mathrm{mV}(10 \mu \mathrm{M}$ bicuculline in the bath). $A$, EPSPs recorded before and after TBS. $B$, Membrane depolarization during TBS. Note that TBS does not reach spike threshold. $C$, Average EPSP changes in five cells after TBS. The control dotted lines are replotted from Figure $2 C . D, R_{\text {in }}$ changes (both above and below $-80 \mathrm{mV}$ ) and changes in $T h_{1}$ and $T h_{2}$ corrected for timedependent changes in control recordings. All data were recorded 15 min after TBS (same cells as in $C$ ).

ported in Figures 2 and 7 suggest that membrane depolarization during TBS plays an important role in the subsequent potentiation of EPSPs and intrinsic excitability. The effect of membrane depolarization was further investigated by delivering TBS from a hyperpolarized membrane potential $(-90 \mathrm{mV})$ (Fig. $8 A)$. During TBS (Fig. $8 B$ ), burst membrane potential settled at $-71.1 \pm 3.2$ $\mathrm{mV}(n=6)$. After TBS, EPSPs tended to decrease (Fig. 8C,D), although the change was not statistically significant $(p>0.3)$.

When the effect of membrane depolarization in different experimental conditions was considered (Fig. $9 A_{1}$ ), a direct relationship between mean TBS burst depolarization and the magnitude of EPSP potentiation was observed. Potentiation of intrinsic excitability (Fig. 9B $B_{1}$ ) showed a lower threshold than potentiation of EPSP or synaptic conductance, as also suggested by the plot in Figure $6 \mathrm{~A}$. As well as membrane depolarization, the spikes may themselves enhance the induction of synaptic plasticity (Thomas et al., 1998; Linden, 1999). Optimal EPSP potentiation was associated with high spike frequency (Fig. $9 A_{2}, B_{2}$ ), whereas intrinsic excitability was already potentiated to the maximum at low spike frequency. The implications of membrane depolarization and spike discharge for mossy fiber-granule cell plasticity are considered in Discussion.

\section{The role of NMDA receptors}

Voltage-dependent NMDA receptor activation is the principal factor responsible for LTP induction (Bliss and Collingridge, 1993). It was therefore interesting to investigate whether potentiation of both EPSP and intrinsic granule cells excitability depended on NMDA receptor activation. Application of the NMDA receptor blockers, $100 \mu \mathrm{M}$ APV and $50 \mu \mathrm{M}$ 7-Cl-kyn (Fig. 10), depressed EPSP temporal summation (Fig. 10B $B_{1}$ (D'Angelo et al., 1995). During TBS applied from $-70 \mathrm{mV}$, spike threshold was reached in three of six cells. In the remaining three cells, mean burst depolarization was $-57.5 \pm 6.5 \mathrm{mV}(n=3)$. None of these cells showed any potentiation of EPSPs or intrinsic excitability (compare Fig. 9). 
A1

Figure 9. LTP dependence on voltage and spike frequency. $A_{1}$, Magnitude of EPSP amplitude changes as a function of depolarization $\left(A_{1}\right)$ or spike frequency $\left(A_{2}\right)$ during TBS. $\triangle$, Strong TBS in $10 \mu \mathrm{M}$ bicuculline (as in

Fig. $2 A_{2}$ ); $\bigcirc$, weak TBS in $10 \mu \mathrm{M}$ bicuculline (as in Fig. $\left.2 A_{1}\right) ; \diamond$, TBS in bicuculline-free solution (as in Fig. 7); $\square$, TBS from $-90 \mathrm{mV}$ in $10 \mu \mathrm{M}$ bicuculline (as in Fig. $8)$. In $A_{1}$, synaptic current changes in voltage-clamp recordings with pairing at -60 or $-40 \mathrm{mV}$ are shown for comparison $(\boldsymbol{\Delta})$ (data from D'Angelo et al., 1999). $B_{1}, B_{2}$, Normalized changes in EPSP (solid line), $R_{\text {in }}$ (dashed line), and spike threshold $\left(\mathrm{Th}_{1} ;\right.$ dotted line) as a function of depolarization $\left(B_{1}\right)$ or spike frequency $\left(B_{2}\right)$ during TBS. EPSP and $T h_{1}$ data have been adjusted for time-dependent changes in control recordings. Note that changes in $R_{\text {in }}$ and $T h_{1}$ occur earlier than those in EPSPs. All data in this figure were recorded $15 \mathrm{~min}$ after TBS.

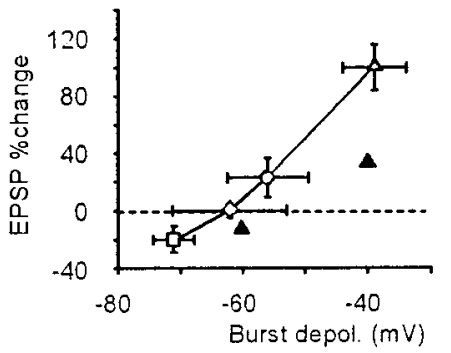

B1

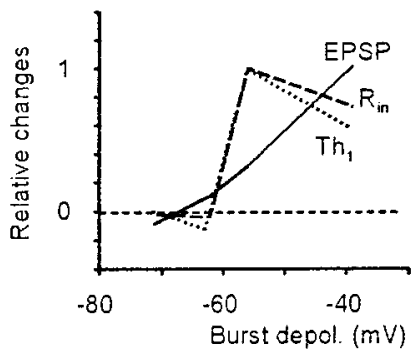

$\mathrm{A} 2$

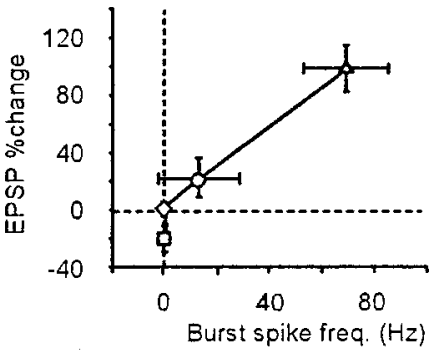

B2

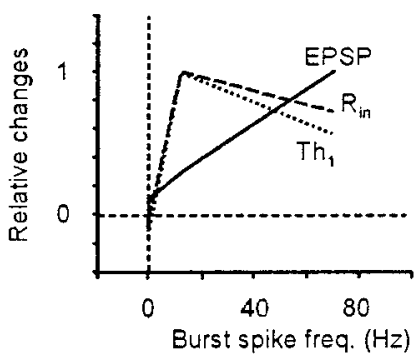

$\mathrm{A}_{1}$

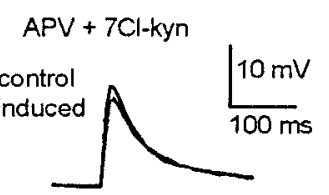

$\mathrm{A} 2$

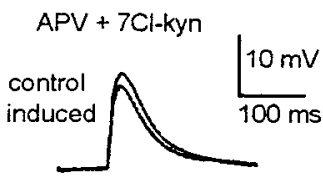

C

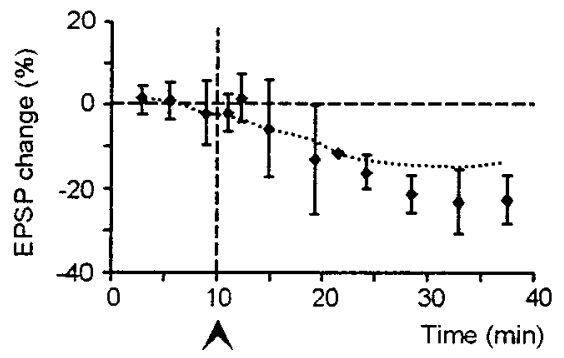

$\mathrm{B}_{1}$

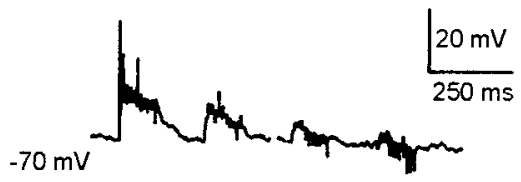

$\mathrm{B} 2$

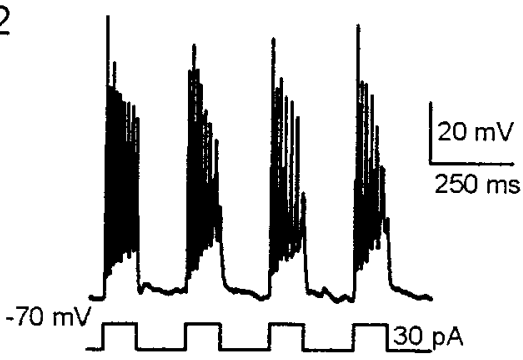

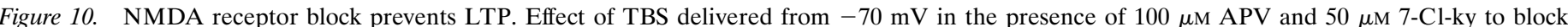

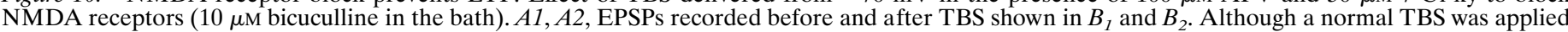

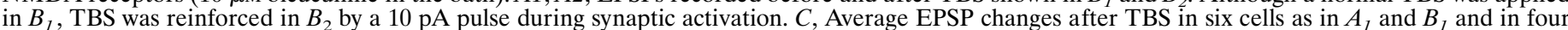

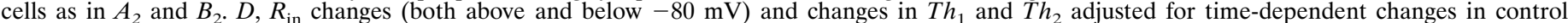
recordings. All data were recorded 15 min after TBS (same cells as in $C$ ). 
In an additional four experiments (Fig. $10 A_{2}$ ), membrane depolarization was reinforced by associating TBS with depolarizing current pulses (Fig. $10 B_{2}$ ). In these experiments neither EPSP nor intrinsic excitability potentiation were induced. The cumulative results of the experiments in Figure 10, $A$ and $B$, are shown in Figure 10, $C$ and $D$. These results indicate that although NMDA receptors reinforce membrane depolarization during repetitive stimulation, they are needed to induce potentiation of EPSPs and postsynaptic responsiveness through a mechanism that differs from their direct depolarizing action and presumably involves an increase in $\mathrm{Ca}^{2+}$ influx and the consequent activation of $\mathrm{Ca}^{2+}$. dependent processes.

\section{DISCUSSION}

This paper demonstrates the potentiation of intrinsic excitability in cerebellar granule cells after high-frequency mossy fiber stimulation. The apparent input resistance $\left(R_{\text {in }}\right)$ increased and spike threshold decreased, enhancing granule cell synaptic excitation. Potentiation of intrinsic excitability could coexist with potentiation of synaptic efficacy, and both depended on NMDA receptor activation.

Potentiation of granule cell intrinsic excitability was induced between -60 and $-40 \mathrm{mV}$. In this potential range, granule cell NMDA receptors activate sizeable conductance (D'Angelo et al., 1995), probably because the NR2C subunit confers low sensitivity to $\mathrm{Mg}^{2+}$ block (Monyer et al., 1994). The main action of NMDA receptors could be that of gating $\mathrm{Ca}^{2+}$ influx (in fact, in whole-cell recordings performed with pipettes containing $10 \mathrm{~mm}$ BAPTA, any excitability change was prevented; $n=5$ ) (E. D'Angelo and P. Rossi, unpublished observation). In addition, NMDA receptors enhanced membrane depolarization (Fig. 10).

Synaptic conductance needed stronger depolarization (approximately $-40 \mathrm{mV}$ ) than intrinsic excitability to be potentiated [see also D'Angelo et al. (1999)]. A discriminating factor between these two aspects of potentiation may be the intensity of the NMDA current, which rises steeply between -60 and $-40 \mathrm{mV}$. Another discriminating factor may be spikes (Thomas et al., 1998; Linden, 1999). Spikes were frequent when LTP included synaptic conductance potentiation, whereas they were rare or absent when potentiation of intrinsic excitability was prominent. Spikes may favor the induction of plasticity through a $\mathrm{Na}^{+}$-dependent enhancement of the NMDA current (Yu and Salter, 1998) and by activating voltagedependent $\mathrm{Ca}^{2+}$ channels (Magee and Johnston, 1997; Markram et al., 1997; Aizenmann et al., 1998; Aizenmann and Linden, 2000). It should be noted that spikes alone were not sufficient to induce synaptic plasticity, as demonstrated by recordings in which NMDA receptors were blocked.

The control of granule cell synaptic excitation proved critical in allowing a voltage- and NMDA receptor-dependent regulation of plasticity. On the one hand, granule cell excitation was finely modulated by the intensity [and frequency; see D'Angelo et al., 1995) of repetitive mossy fiber discharge. The physiological significance of this mechanism is suggested by the observation that repetitive mossy fiber discharge changes in relation to specific behavioral states in vivo (Kase et al., 1980; Pellerin and Lamarre, 1997; Hartmann and Bower, 1998). On the other hand, granule cell excitation was reduced through both tonic and phasic mechanisms of synaptic inhibition mediated by Golgi cells (Fig. 1) (Brickley et al., 1996). Although Golgi cell inhibition prevented mossy fibergranule cell plasticity, the efficiency of this process in vivo remains speculative. Golgi cell activity reflects excitation in a large population of mossy and parallel fibers (Eccles et al., 1967; van Kan et al., 1993; Vos et al., 1999), the discharge of which is probably less synchronous than in our experiments (in which the whole afferent fiber bundle was excited). Thus Golgi cells should dynamically modulate mossy fiber-granule cell plasticity rather than exert an all-or-none preventative action. Moreover, local depression of GABA release by high-frequency mossy fiber discharge (Mitchell and Silver, 2000) may favor LTP induction at specific synapses by contrasting background granule cell inhibition (Davies et al., 1991).
A closer understanding of Golgi cell functions seems crucial to clarify the physiological induction mechanism of mossy fiber-granule cell plasticity.

The increase in granule cell input resistance and spike prepotential occurred in a limited membrane potential region, suggesting that voltage-dependent conductances involved in spike generation were changed. Although at present there is no direct evidence to implicate any specific membrane conductance, it should be noted that an increased $\mathrm{Na}^{+}$current and a decreased $\mathrm{K}^{+}$current may account for a reduced firing threshold, as demonstrated recently in cell culture (Desai et al., 1999). A Ca ${ }^{2+}$ current-dependent effect, which might occur in hippocampal pyramidal neurons (Wathey et al., 1992) or in cerebellar deep nuclear cells (Aizenmann and Linden, 2000), seems less likely to occur in cerebellar granule cells because their $\mathrm{Ca}^{2+}$ currents activate once the spike has already been generated (D'Angelo et al., 1998). It should be noted that persistent depression of synaptic inhibition (as reported in hippocampal E-S potentiation) (Abraham et al., 1987; Chavez-Noriega e al., 1990; Breakwell et al., 1995) did not significantly contribute to enhance granule cell excitation.

Potentiation of intrinsic excitability and synaptic conductance cooperated to strengthen EPSP-spike coupling and to increase the reliability of spike generation during synaptic transmission (Daoudal et al., 1999). However, the functional significance of intrinsic excitability potentiation may differ partly from that of synaptic conductance potentiation. First, because potentiation of intrinsic excitability could be achieved at a relatively low threshold, it may have a compensatory effect by restoring granule cell readiness in conditions of weak synaptic excitation (Fregnac, 1998). An increased excitability in turn may facilitate the subsequent induction of synaptic conductance potentiation. Second, because the granule cell has a compact electrotonic structure and a marginal potential loss is expected from dendritic endings to soma (Gabbiani et al., 1994; D’Angelo et al., 1995; Silver et al., 1996), potentiated excitability should affect neuronal responsiveness as a whole. Conversely, synaptic conductance changes are thought to be synapse specific (Bliss and Collingridge, 1993).

By allowing learning and storage of activity patterns at specific synapses while maintaining neuronal firing within an appropriate operating window, the combination of changes in synaptic conductance and intrinsic excitation may optimize information transfer and network computation (Stemmler and Koch, 1999). Although plasticity at the mossy fiber-granule cell synapse was not included in Marr's (1969) original model of the cerebellum, it may have important implications for cerebellar control of motor coordination (Arbib et al., 1998; Schweighofer et al., 1998; N. Schweighofer, personal communication).

\section{REFERENCES}

Abraham WC, Gustafsson B, Wigström H (1987) Long-term potentiation involves enhanced synaptic excitation relative to synaptic inhibition in guinea-pig hippocampus. J Physiol (Lond) 394:367-380.

Aizenmann C, Linden DJ (2000) Rapid, synaptically driven increases in the intrinsic excitability of cerebellar nuclear neurons. Nat Neurosci 3:109-111.

Aizenmann C, Manis PB, Linden DJ (1998) Polarity of long-term synaptic changes is related to postsynaptic spike firing at a cerebellar inhibitory synapse. Neuron 21:827-835.

Andersen P, Sundberg SH, Sveen O, Swann JW, Wigström H (1980) Possible mechanisms for long-lasting potentiation of synaptic transmission in hippocampal slices from guinea-pigs. J Physiol (Lond) 301:463-482.

Arbib MA, Erdi P, Szentagothai J (1998) Cerebellum. In: Neural organization: structure, function, and dynamics, pp 261-302. London: MIT.

Bear MF, Malenka RC (1994) Synaptic plasticity: LTP and LTD. Curr Opin Neurobiol 4:389-399.

Bliss TVP, Collingridge GL (1993) A synaptic model of memory: longterm potentiation in the hippocampus. Nature 361:31-39.

Bliss TVP, Lömo T (1973) Long-lasting potentiation of synaptic transmission in the dentate area of the anaesthetised rabbit following stimulation of the perforant path. J Physiol (Lond) 232:331-356.

Breakwell NA, Rowan MJ, Anwyl R (1996) Metabotropic glutamate receptor dependent EPSP and EPSP-spike potentiation in area CA1 of the submerged rat hippocampal slice. J Neurophysiol 76:3126-3135.

Brickley SG, Cull-Candy SG, Farrant M (1996) Development of a tonic 
form of synaptic inhibition in rat cerebellar granule cells resulting from persistent activation of GABA receptors. J Physiol (Lond) 497:753-759.

Chavez-Noriega LE, Halliwell JV, Bliss TVP (1990) A decreased firing threshold observed after induction of the EPSP-spike (E-S) component of long-term potentiation in rat hippocampal slices. Exp Brain Res 79:633-641.

Christofi G, Nowicky AV, Bolsover SR, Bindman LJ (1993) The postsynaptic induction of non-associative long-term depression of excitatory transmission in rat hippocampal slices. J Neurophysiol 69:219-229.

D’Angelo E, De Filippi G, Rossi P, Taglietti V (1995) Synaptic excitation of individual rat cerebellar granule cells in situ: evidence for the role of NMDA receptors. J Physiol (Lond) 484:397-413.

D'Angelo E, De Filippi G, Rossi P, Taglietti V (1998) Ionic mechanism of electroresponsiveness in cerebellar granule cells implicates the action of a persistent sodium current. J Neurophysiol 80:493-503.

D'Angelo E, Rossi P, Armano S, Taglietti V (1999) Evidence for NMDA and mGlu receptor-dependent long-term potentiation of mossy fibergranule cell transmission in rat cerebellum. J Neurophysiol 81:277-287.

Daoudal G, Handa Y, Ferrand N, Debanne D (1999) Synergy between bi-directional changes in excitability and synaptic plasticity in the area CA1 of the rat hippocampus in vitro. Soc Neurosci Abstr 25:182.1.

Davies CH, Starkey SJ, Pozza MF, Collingridge GL (1991) GABA autoreceptors regulate the induction of LTP. Nature 349:609-611.

Desai NS, Rutherford LC, Turrigiano GG (1999) Plasticity in the intrinsic excitability of cortical pyramidal neurons. Nat Neurosci 2:515-520.

Eccles JC, Ito M, Szentagothai J (1967) The cerebellum as a neuronal machine. Berlin: Springer.

Edwards FA, Konnerth A, Sackmann B, Takahashi TA (1989) A thin slice preparation for patch-clamp recordings from neurones of the mammalian central nervous system. Pflügers Arch 414:600-612.

Fregnac Y (1998) Homeostasis or synaptic plasticity? Nature 391:845-846.

Gabbiani F, Midtgaard J, Knoepfel T (1994) Synaptic integration in a model of cerebellar granule cells. J Neurophysiol 72:999-1009.

Hartmann MJ, Bower JM (1998) Oscillatory activity in cerebellar hemispheres on unrestrained rats. J Neurophysiol 80:1598-1604.

Horn D, Marty A (1988) Muscarinic activation of ionic currents measured by a new whole-cell recording method. J Gen Physiol 92:145-159.

Kase M, Miller DC, Noda H (1980) Discharges of Purkinje cells and mossy fibers in the cerebellar vermis of the monkey during saccadic eye movements. J Physiol (Lond) 300:539-555.

Kelso SR, Ganong AH, Brown TH (1986) Hebbian synapses in the hippocampus. Proc Natl Acad Sci USA 83:5326-5330.

Linden DJ (1999) The return of the spike: postsynaptic action potentials and the induction of LTP and LTD. Neuron 22:661-666.

Magistretti J, Mantegazza M, de Curtis M, Wanke E (1998) Modalities of distortion of physiological voltage signals by patch-clamp amplifiers: a modelling study. Biophys J 74:831-842.
Magee JC, Johnston D (1997) A synaptically controlled, associative signal for Hebbian plasticity in hippocampal neurons. Science 275:209-213.

Markram H, Lubke J, Frotscher M, Sackmann B (1997) Regulation of synaptic efficacy by coincidence of postsynaptic APs and EPSPs. Science 275:213-215.

Marr D (1969) A theory of cerebellar cortex. J Physiol (Lond) 202:437-470.

Mitchell SJ, Silver RA (2000) Glutamate spillover suppresses inhibition by activating presynaptic mGluRs. Nature 404:498-502.

Monyer H, Burnashev N, Laurie DJ, Sakmann B, Seeburg PH (1994) Developmental and regional expression in the rat brain and functional properties of four NMDA receptors. Neuron 12:529-540.

Pellerin P-P, Lamarre Y (1997) Local field potential oscillations in primate cerebellar cortex during voluntary movement. J Neurophysiol 78:3502-3507.

Pockett S, Brookes NH, Bindman NJ (1990) Long-term depression at synapses in slices of rat hippocampus can be induced by bursts of postsynaptic activity. Exp Brain Res 80:196-200.

Pugliese AM, Ballerini L, Passani MB, Corradetti R (1994) EPSP-spike potentiation during primed burst-induced long-term potentiation in the CA1 region of rat hippocampal slices. Neuroscience 62:1021-1032.

Schweighofer N, Spoelstra J, Arbib M, Kawato M (1998) Role of cerebellum in reaching movements in humans. I. A neural model of the intermediate cerebellum. Eur J Neurosci 10:95-105.

Silver RA, Cull-Candy SG, Takahashi T (1996) Non-NMDA glutamate receptor occupancy and open probability at a rat cerebellar synapse with single and multiple release sites. J Physiol (Lond) 494:231-250.

Spitzer NC (1991) A developmental handshake: neuronal control of ionic currents and their control of neuronal differentiation. J Neurobiol 22:659-673.

Stemmler M, Koch C (1999) How voltage-dependent conductances can adapt to maximize the information encoded by neuronal firing rate. Nat Neurosci 2:521-527.

Thomas MJ, Watabe AM, Moody TD, Makhinson M, O’Dell TJ (1998) Postsynaptic complex spike bursting enables the induction of LTP by theta frequency synaptic stimulation. J Neurosci 18:7118-7216.

Turrigiano G, Abbott LF, Marder E (1994) Activity-dependent changes in the intrinsic properties of cultured neurons. Science 264:974-977.

van Kan PL, Gibson AR, Houk JC (1993) Movement-related inputs in intermediate cerebellum of monkeys. J Neurophysiol 69:74-94.

Vos BP, Volny-Luraghi A, De Schutter E (1999) Cerebellar Golgi cells in the rat: receptive fields and timing of responses to facial stimulation. Eur J Neurosci 11:2621-2634.

Wathey JC, Lytton WW, Jester JM, Sejinowski TJ (1992) Computer simulation of EPSP-spike (E-S) potentiation in hippocampal CA1 pyramidal cells. J Neurosci 12:607-618.

Yu X-M, Salter MW (1998) Gain control of NMDA-receptor currents by intracellular sodium. Nature 375:469-474. 